\title{
Flavonoids from Albizia procera
}

\author{
F. R. Melek ${ }^{1 *}$, Neveen S. Ghaly ${ }^{1}$, M. El-Kady ${ }^{2}$, Marian Nabil ${ }^{1}$ \\ ${ }^{1}$ Chemistry of Natural Compounds Department, National Research Center, Dokki 12622, Giza, Egypt \\ ${ }^{2}$ Chemistry Department, Faculty of Science, Ain Shams University, Abbassia, 11566, Cairo. Egypt.
}

\section{A R T I C L E I N F O}

Article history:

Received 17 May 2011

Accepted 05 July 2011

Keywords:

Albizia procera;

Leguminosae;

Flavonoids.

\begin{abstract}
A B S T R A C T
The flavonoids luteolin, quercetin-3-O- $\alpha$-L-rhamnopyranoside, quercetin-3-O- $\beta$ D-galactopyranoside, quercetin-3-O- $\beta$-D-glucopyranoside and quercetin-3-O- $(2$ "O- $\beta$-D-xylopyranosyl)- $\beta$-D-galactopyranoside, were isolated from the methanolic extract of the leaves of Albizia procera using chromatographic methods. Identification of the flavonoid constituents was carried by analyzing their spectroscopic data and/or by comparing these data with the reported ones in the literature.
\end{abstract}

\section{Introduction}

The genus Albizia (Leguminosae) comprises about 150 species widely distributed in Africa and Central and South America. In Africa, several Albizia species are used in folk medicine for the treatment of rheumatism, stomach trouble, cough, diarrhea, wounds and as anthelmintic ${ }^{1}$.

In traditional Chinese medicine, Albizia members are used for the treatment of insominia, irritability, wounds and as antidysentric, antiseptic and antitubercular ${ }^{2}$. Phytochemical studies carried out on plants of genus Albizia, have revealed them as sources of different groups of natural products, triterpenoid saponins ${ }^{3-11}$, diterpenoids $^{12}$, flavonoids ${ }^{13-22}$, lignans ${ }^{21,23}$, phenolic glycosides $^{24,25}$ and pyridineglycoside ${ }^{26}$.

As a part of our continuous investigation on secondary metabolites from Albizia species ${ }^{9,11}$, we describe in this report the isolation of five flavonoids from the methanolic extract of $A$. procera.

\section{Materials and Methods}

\section{General experimental procedure}

Column chromatography was run using silica gel 60 (Merck) and Sephadex LH-20 (Sigma). TLC was carried out using silica gel (Merck) as stationary phase. Chromatograms were first visualized by observation under $\mathrm{UV}$ and then spraying with $\mathrm{FeCl}_{3}$ spray reagent. NMR spectra were recorded on a JEOL EX $500 \mathrm{MHz}$ and a Varian GEMINT $200 \mathrm{MHz}$ spectrometers. Chemical shifts were given on $\delta$-scale with TMS as internal standard.

\footnotetext{
* Corresponding author.

E-mail address: frmelek@ hotmail.com.

Tel: 010-5152568
}

\section{Plant material}

The leaves of $A$. procera were collected from the zoological garden in Giza, Egypt. Plant identification was confirmed by Mrs. T. Labib, head specialist for plant identification in El-Orman public garden, Giza, Egypt.

\section{Extraction and Isolation}

Air-dried and powdered leaves (750 g) of A. procera were extracted with chloroform $(2 \mathrm{~L} \times 2)$ and then with $\mathrm{MeOH}(2 \mathrm{~L} \times 2)$ at room temperature. The total alcoholic extract was evaporated to dryness under reduced pressure. The residue (30 g) was suspended in distilled water $(500 \mathrm{ml})$ and successively partitioned with $\mathrm{CH}_{2} \mathrm{Cl}_{2}(500 \mathrm{ml} \times 2)$, EtOAc (700 ml x 3) and $\mathrm{BuOH}$ $(700 \mathrm{ml} \mathrm{x} \mathrm{3)}$. The $\mathrm{BuOH}$ fraction (10 g) was subjected to silica gel column chromatography. The column was eluted first with $\mathrm{CH}_{2} \mathrm{Cl}_{2}$ and then with $\mathrm{CH}_{2} \mathrm{Cl}_{2}-\mathrm{MeOH}$ mixture with increasing amount of $\mathrm{MeOH}$ to $20 \%$. A total 40 fractions $100 \mathrm{ml}$ each were collected. The fractions were monitored by silica gel TLC plates using solvent system $\mathrm{CHCl}_{3}-\mathrm{MeOH}-\mathrm{H}_{2} \mathrm{O}$ (60: 30: 5) and examined under UV light followed by spraying with $\mathrm{FeCl}_{3}$ reagent. The fractions which eluted with $10 \%$ $\mathrm{MeOH}$ were combined after TLC analysis contained compound $\mathbf{1}$ as a major component. The combined fraction was repeatedly chromatographed on Sephadex LH-20 column using methanol as eluent to yield pure $\mathbf{1}$ (40 mg). The fractions which eluted from silica gel column with $12-14 \% \mathrm{MeOH}$ were combined contained compound $\mathbf{2}$ as a major component. The combined fraction was repeatedly chromatographed on Sephadex LH-20 column using methanol as eluent to yield pure $\mathbf{2}$ 
(50 mg). The fractions which eluted with $15 \% \mathrm{MeOH}$ were combined. The combined fraction was subjected to preparative paper chromatography eluted with solvent system n-Butanol - Acetic acid - Water (4: 1: 5, upper layer) followed by repeated purification on Sephadex LH-20 column eluted with $\mathrm{MeOH}$ to yield inseparable mixture of 3 and $\mathbf{4}(30 \mathrm{mg})$. The fractions which eluted from the silica gel column with $17 \%$ methanol were combined after TLC analysis and found to contain compound $\mathbf{5}$ as a major constituent. The combined fraction was chromatographed on Sephadex LH-20 column chromatography using methanol as eluent to yield pure $5(25 \mathrm{mg})$.

\section{Luteolin (1)}

Amorphous yellow powder. ${ }^{1} \mathrm{HNMR}(500 \mathrm{MHz}$, acetone- $\left.\mathrm{d}_{6}\right) \delta: 12.96(1 \mathrm{H}, \mathrm{s}, \mathrm{OH}-5), 7.46(1 \mathrm{H}, \mathrm{d}, J=2.3$ $\left.\mathrm{Hz}, \mathrm{H}-2^{\prime}\right), 7.44\left(1 \mathrm{H}, \mathrm{dd}, J=8.4,2.3 \mathrm{~Hz}, \mathrm{H}-6^{\prime}\right), 6.96(1 \mathrm{H}$, $\left.\mathrm{d}, J=8.4 \mathrm{~Hz}, \mathrm{H}-5^{\prime}\right), 6.55(1 \mathrm{H}, \mathrm{s}, \mathrm{H}-3), 6.49(1 \mathrm{H}, \mathrm{d}, J=$ $2.3 \mathrm{~Hz}, \mathrm{H}-8), 6.21(1 \mathrm{H}, \mathrm{d}, J=2.3 \mathrm{~Hz}, \mathrm{H}-6),(\mathrm{OH}-7$ \& $\mathrm{OH}-4$ ' were not detected).

\section{Quercetin-3-O- $\alpha$-L-rhamnopyranoside (2)}

Amorphous yellow powder. ${ }^{1} \mathrm{HNMR}(500 \mathrm{MHz}$, acetone- $\left.\mathrm{d}_{6}\right) \delta: 12.68(1 \mathrm{H}, \mathrm{s}, \mathrm{OH}-5), 7.46(1 \mathrm{H}, \mathrm{d}, J=2.3$ $\left.\mathrm{Hz}, \mathrm{H}-2^{\prime}\right), 7.34\left(1 \mathrm{H}, \mathrm{dd}, J=8.4,2.3 \mathrm{~Hz}, \mathrm{H}-6^{\prime}\right), 6.95(1 \mathrm{H}$, d, $\left.J=8.4 \mathrm{~Hz}, \mathrm{H}-5^{\prime}\right), 6.43(1 \mathrm{H}, \mathrm{d}, J=2.3 \mathrm{~Hz}, \mathrm{H}-8), 6.22$ $(1 \mathrm{H}, \mathrm{d}, J=2.3 \mathrm{~Hz}, \mathrm{H}-6), 5.45(1 \mathrm{H}, \mathrm{d}, J=1.5 \mathrm{~Hz}, \mathrm{Rha} \mathrm{H}-$ 1"), 3.30-3.32 (Rha H-2" - H-5"), 0.88 (3H, d, $J=5.6$ $\mathrm{Hz}$, Rha Me-6"), (OH-7 \& OH-4' were not detected). ${ }^{13} \mathrm{CNMR}\left(500 \mathrm{MHz}\right.$, acetone- $\mathrm{d}_{6}$ ) $\delta: 178.5$ (C-4), 164.5 (C-7), 162.3 (C-5), 157.6 (C-2), 157.2 (C-9), 148.5 (C4'), 145.1 (C-3'), 135.0 (C-3), 121.9 (C-1'), 121.6 (C-6'), 115.9 (C-2'), 115.3 (C-5') 105.0 (C-10), 102.0 (C-1"), 98.7 (C-6), 93.7 (C-8), 71.3 (C-4"), 70.6 (C-2"), 70.5 (C-3"), 70.5 (C-5"), 16.9 (C-6").

\section{Quercetin-3-O-p-D-galactopyranoside (3)}

Amorphous yellow powder. ${ }^{1} \mathrm{HNMR}(500 \mathrm{MHz}$, acetone- $\left.\mathrm{d}_{6}+\mathrm{D}_{2} \mathrm{O}\right) \delta: 7.93\left(1 \mathrm{H}, \mathrm{d}, \mathrm{J}=2.3 \mathrm{~Hz}, \mathrm{H}-2^{\prime}\right), 7.52$ $\left(1 \mathrm{H}, \mathrm{dd}, J=8.6,2.3 \mathrm{~Hz}, \mathrm{H}-6^{\prime}\right), 6.88(1 \mathrm{H}, \mathrm{d}, J=8.6 \mathrm{~Hz}, \mathrm{H}-$ $\left.5^{\prime}\right), 6.45(1 \mathrm{H}, \mathrm{d}, J=2.5 \mathrm{~Hz}, \mathrm{H}-8), 6.20(1 \mathrm{H}, \mathrm{d}, J=2.3 \mathrm{~Hz}$, H-6), $5.12(1 \mathrm{H}, \mathrm{d}, J=7.7 \mathrm{~Hz}, \mathrm{Gal} \mathrm{H}-1 "), 3.89(1 \mathrm{H}, \mathrm{d}$, $J=3.1 \mathrm{~Hz}, \mathrm{Gal} \mathrm{H}-5 "), 3.82(1 \mathrm{H}, \mathrm{t}, J=7.7 \mathrm{~Hz}, \mathrm{Gal} \mathrm{H}-6 " \mathrm{a})$, (OH-7, OH-4' \& OH-5 were not detected). ${ }^{13} \mathrm{CNMR}$ $\left(500 \mathrm{MHz}\right.$, acetone- $\left.\mathrm{d}_{6}+\mathrm{D}_{2} \mathrm{O}\right) \delta: 178.1(\mathrm{C}-4), 164.8(\mathrm{C}-$ 7), 161.4 (C-5), 157.3 (C-2), 157.0 (C-9), 148.8 (C-4'), 144.6 (C-3'), 134.5 (C-3), 121.6 (C-1'), $121.4\left(\mathrm{C}^{\prime} 6^{\prime}\right)$, 116.9 (C-5'), 115.2 (C-2') 104.2 (C-10), 104.0 (C-1"), 99.0 (C-6), 94.0 (C-8), 75.6 (C-5"), 73.6 (C-3"), 71.8 (C-2"), 68.1 (C-4"), 60.2 (C-6").

\section{Quercetin-3-O-p-D-glucopyranoside (4)}

Amorphous yellow powder. ${ }^{1} \mathrm{HNMR}(500 \mathrm{MHz}$, acetone- $\left.\mathrm{d}_{6}+\mathrm{D}_{2} \mathrm{O}\right) \delta: 7.79\left(1 \mathrm{H}, \mathrm{d}, \mathrm{J}=2.3 \mathrm{~Hz}, \mathrm{H}-2^{\prime}\right), 7.52$ $\left(1 \mathrm{H}, \mathrm{dd}, J=8.6,2.3 \mathrm{~Hz}, \mathrm{H}-6{ }^{\prime}\right), 6.89(1 \mathrm{H}, \mathrm{d}, J=8.6 \mathrm{~Hz}, \mathrm{H}-$ $\left.5^{\prime}\right), 6.44(1 \mathrm{H}, \mathrm{d}, J=2.5 \mathrm{~Hz}, \mathrm{H}-8), 6.20(1 \mathrm{H}, \mathrm{d}, J=2.5 \mathrm{~Hz}$, H-6), $5.21(1 \mathrm{H}, \mathrm{d}, J=7.6 \mathrm{~Hz}, \mathrm{Glc} \mathrm{H}-1 "), 3.23(1 \mathrm{H}, \mathrm{m}$, Glc $\mathrm{H}-5 "),(\mathrm{OH}-7, \mathrm{OH}-4$ ' \& $\mathrm{OH}-5$ were not detected). ${ }^{13}$ CNMR (500 MHz, acetone- $\left.\mathrm{d}_{6}+\mathrm{D}_{2} \mathrm{O}\right) \delta: 178.1(\mathrm{C}-4)$,
164.9 (C-7), 161.4 (C-5), 157.3 (C-2), 157.0 (C-9), 148.8 (C-4'), $144.6\left(\mathrm{C}-3^{\prime}\right), 134.5$ (C-3), $121.6\left(\mathrm{C}-1^{\prime}\right)$, 121.4 (C-6'), 116.9 (C-5'), 115.2 (C-2') 104.2 (C-10), 103.0 (C-1"), 99.0 (C-6), 94.0 (C-8), 76.8 (C-5"), 76.6 (C-3"), 74.3 (C-2"), 69.5 (C-4"), 61.0 (C-6").

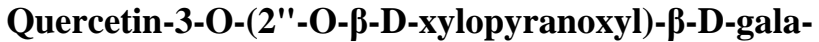
ctopyranoside (5)

Amorphous yellow powder. ${ }^{1} \mathrm{HNMR}(500 \mathrm{MHz}$, DMSO-d $\left.{ }_{6}\right) \delta: 12.67(1 \mathrm{H}, \mathrm{s}, \mathrm{OH}-5), 7.68(1 \mathrm{H}, \mathrm{d}, J=8.4$ Hz, H-6'), 7.47 (1H, bs, H-2'), $6.78(1 \mathrm{H}, \mathrm{d}, J=8.4 \mathrm{~Hz}, \mathrm{H}-$ $\left.5^{\prime}\right), 6.35(1 \mathrm{H}, \mathrm{bs}, \mathrm{H}-8), 6.14(1 \mathrm{H}, \mathrm{bs}, \mathrm{H}-6), 5.66(1 \mathrm{H}, \mathrm{d}$, $J=7.7 \mathrm{~Hz}, \mathrm{Gal} \mathrm{H}-1 "), 4.53$ (1H, d, $\left.J=6.9 \mathrm{~Hz}, \mathrm{Xyl} \mathrm{H}-1^{\prime \prime \prime}\right)$, (OH-7 \& OH-4' were not detected). ${ }^{13}$ CNMR (500 $\mathrm{MHz}$, acetone- $\left.\mathrm{d}_{6}+\mathrm{D}_{2} \mathrm{O}\right) \delta: 178.3(\mathrm{C}-4), 164.4(\mathrm{C}-7)$, 161.5 (C-5), 156.9 (C-2, 9), 148.6 (C-4'), 144.7 (C-3'), 133.8 (C-3), 122.0 (C-1'), 122.6 (C-6'), $116.4\left(\mathrm{C}^{\prime} 5^{\prime}\right)$, 115.4 (C-2') 104.4 (C-10), 104.2 (C-1"'), 100.0 (C-1"), 99.6 (C-6), 93.9 (C-8), 79.4 (C-2"), 75.4 (C-2"', 3"'), 73.7 (C-5"), 73.6 (C-3"), 69.5 (C-4"), 68.2 (C-4"'), 65.1 (C-5"'), 60.0 (C-6").

\section{General method for acid hydrolysis:}

Each glycoside $(2 \mathrm{mg})$ in $3 \mathrm{ml} 2 \mathrm{~N} \mathrm{HCl}$ and $3 \mathrm{ml}$ methanol was heated at $100^{\circ} \mathrm{C}$ for $2 \mathrm{~h}$. The mixture was left to cool, diluted with $\mathrm{H}_{2} \mathrm{O}$ and extracted twice with ethyl acetate. From the ethyl acetate layer, the aglycone was detected against reference sample by TLC (chloroform-methanol, 5: 1). The aqueous layer was repeatedly diluted with methanol and evaporated to dryness. The residue was investigated to detect the sugar by paper chromatography (PC) using solvent system $\mathrm{n}-\mathrm{BuOH}-\mathrm{HOAc}-\mathrm{H}_{2} \mathrm{O}$ (4: 1: 5, upper layer).

\section{Results and Discussion}

The methanolic leaf extract of $A$. procera was dissolved in water and the aqueous solution was successively extracted with chloroform, ethyl acetate then n-butanol. The material from the butanol extract was chromatographed on silica gel column chromatography. The collected fractions were examined by TLC and similar fractions were combined. The semi-purified compounds from the combined fractions were then purified using Sephadex-LH20 column chromatography and preparative paper chromatography to afford the flavonoids luteolin (1), quercetin 3-O- $\alpha-\mathrm{L}-$ rhamnopyranoside (2) quercetin 3-O- $\beta$-Dgalactopyranoside (3) quercetin 3-O- $\beta$-Dglucopyranoside (4) and quercetin 3-O-(2"-O- $\beta$-Dxyloxyl)- $\beta$-D-galactopyranoside (5). The structures of the isolates were determined by acid hydrolysis, ${ }^{1} \mathrm{H}$ and ${ }^{13} \mathrm{CNMR}$ spectroscopic analysis and/or comparison with published data.

The flavonoid luteolin $\mathbf{1}$ was characterized by comparison of their spectral data with literature values $^{27}$.

In the ${ }^{1} \mathrm{HNMR}$ spectrum of Quercetin 3-O- $\alpha$-L-rhamnopyranoside 2 , the presence of signals due to three meta coupled protons at $\delta 6.22(1 \mathrm{H}, \mathrm{d}, J=2.3 \mathrm{~Hz}, \mathrm{H}-6), \delta 6.43$ 
$(1 \mathrm{H}, \mathrm{d}, J=2.3 \mathrm{~Hz}, \mathrm{H}-8)$ and $\delta 7.46(1 \mathrm{H}, \mathrm{d}, J=2.3 \mathrm{~Hz}, \mathrm{H}-$ $\left.2^{\prime}\right)$ as well as two ortho-coupled protons at $\delta 6.95(1 \mathrm{H}$, $\left.\mathrm{d}, J=8.4 \mathrm{~Hz}, \mathrm{H}-5^{\prime}\right)$ and $\delta 7.34(1 \mathrm{H}, \mathrm{dd}, J=8.4,2.3 \mathrm{~Hz}$, H-6') along with carbon signal at $\delta 178.5$ (C-4) in the ${ }^{13} \mathrm{CNMR}$ spectrum, indicated a typical 3', 4', 5, 7tetrahydroxyflavonol skeleton. The two doublets in the ${ }^{1} \mathrm{HNMR}$ spectrum of 2 at $\delta 5.45(1 \mathrm{H}, J=1.5 \mathrm{~Hz})$ and $\delta$ $0.88(3 \mathrm{H}, J=5.6 \mathrm{~Hz})$ were assigned to $\mathrm{H}-1$ " and $\mathrm{H}-6$ " of a rhamnose unit ${ }^{27}$. The ${ }^{13} \mathrm{CNMR}$ data of $\mathbf{2}$ and the result of acid hydrolysis indicated $\alpha$-L-rhamnopyranoside. The attachment of the moiety at $\mathrm{C}-3$ position of the aglycone was revealed from the $\delta$ value of C-3 (135.0 ppm) and that of C-2 (157.6 ppm).

Compound $\mathbf{2}$ was then assigned the structure of quercetin 3-O- $\alpha$-L-rhamnopyranoside based on the above spectral evidences and comparison with literature values $^{28,29}$.

Quercetin-3-O- $\beta$-D-galactopyranoside 3 and Quercetin3-O- $\beta$-D-glucopyranoside $\mathbf{4}$ were obtained as inseparable mixture with compound $\mathbf{3}$ as the major component. The ${ }^{1}$ HNMR spectrum of $\mathbf{3}$ and $\mathbf{4}$ showed two sets of signals due to quercetin moiety. One set of signals was at $\delta 7.93\left(1 \mathrm{H}, \mathrm{d}, \mathrm{J}=2.3 \mathrm{~Hz}, \mathrm{H}-2^{\prime}\right), 7.52(1 \mathrm{H}$, dd, $J=8.6,2.3 \mathrm{~Hz}, \mathrm{H}-6$ '), $6.88\left(1 \mathrm{H}, \mathrm{d}, J=8.6 \mathrm{~Hz}, \mathrm{H}-5^{\prime}\right)$, $6.45(1 \mathrm{H}, \mathrm{d}, J=2.5 \mathrm{~Hz}, \mathrm{H}-8), 6.20(1 \mathrm{H}, \mathrm{d}, J=2.3 \mathrm{~Hz}, \mathrm{H}-$ $6)$. The other set was at $\delta 7.79\left(1 \mathrm{H}, \mathrm{d}, \mathrm{J}=2.3 \mathrm{~Hz}, \mathrm{H}-2^{\prime}\right)$, 7.52 (1H, dd, J=8.6, $2.3 \mathrm{~Hz}, \mathrm{H}-6$ '), 6.89 (1H, d, J=8.6 Hz, H-5'), 6.44 (1H, d, J=2.5 Hz, H-8), 6.20 (1H, d, J= $2.5 \mathrm{~Hz}, \mathrm{H}-6)$. The spectrum also exhibited two proton signals at $\delta 5.12(1 \mathrm{H}, \mathrm{d}, J=7.7 \mathrm{~Hz})$ and $\delta 5.21(1 \mathrm{H}, \mathrm{d}$, $J=7.6 \mathrm{~Hz}$ ) assigned to anomeric proton of $\beta$-galactose and that of $\beta$-glucose, respectively. The ${ }^{13} \mathrm{CNMR}$ spectum of $\mathbf{3}$ and $\mathbf{4}$ showed two sets of signals due to the querctin moiety and two sets of signals attributable to a galactose and glucose moieties, respectively (experimental section). The signals of galactose moiety were at $\delta 104.0\left(\mathrm{C}-1^{\prime \prime}\right), 75.6$ (C-5"), 73.6 (C-3"), 71.8 (C-2"), 68.1 (C-4") and 60.2 (C-6") while the signals due to the glucose moiety were at $\delta 103.0$ (C-1"), 76.8 (C-5"), 76.6 (C-3"), 74.3 (C-2"), 69.5 (C-4"), 61.0 (C6"). Acid hydrolysis of $\mathbf{3}$ and $\mathbf{4}$ afforded quercetin iden- tified by TLC comparison against authentic sample as well as the sugar component D-galactose and D-glucose recognized by paper chromatography against standard samples. The $\beta$-configuration of the anomeric centers was determined as $\beta$ from the $\mathrm{J}_{1,2}$ values and the ${ }^{13} \mathrm{CNMR}$ data indicated pyranose form for the two sugar units. The site attachment of the sugar moiety to C-3 position of quercetin, was established from the $\delta$ value of C-3 resonances at $\delta 134.5$ and C-2 resonances at $\delta$ 157.3 for 3 and 4 . These values agreed well with the literature values ${ }^{28,30}$ and the corresponding ones in the ${ }^{13} \mathrm{CNMR}$ data of compound $\mathbf{2}$ as well as other quercetin3-O-glycosides ${ }^{28,29}$.

Quercetin-3-O-(2"-O- $\beta$-D-xylopyranosyl)- $\beta$-D-galactopyranoside 5 is another quercetin 3-O-glycoside from the characteristic ${ }^{1} \mathrm{H}$ and ${ }^{13} \mathrm{CNMR}$ resonances as well as acid hydrolysis which afforded quercetin moiety and the sugar components D-galactose and D-xylose. The ${ }^{13} \mathrm{CNMR}$ spectrum of $\mathbf{5}$ showed in addition to the resonances of the quercetin moiety, eleven carbon resonances assigned to a 2-O-substituted $\beta$ galactopyranose (C-2", $79.2 \mathrm{ppm}$; C-1", $100.0 \mathrm{ppm})$ and a terminal $\beta$-D-xylopyranose units. The $\beta$-configurations of the anomeric protons of D-galactose and D-xylose were deduced from the $\mathrm{J}_{1,2}$ values for both sugar units. The pyranose form for the sugar units was determined from their ${ }^{13} \mathrm{CNMR}$ data. The attachment of the terminal $\beta$-D-xylopyranosyl unit to the inner $\beta$-D-xylopyranosyl unit was established from the observed downfield position of C-2" and upfield position of C-1" of the inner sugar with reference to the corresponding values for compound 3 ( $\delta$ C-2", 71.8; $\delta$ C-1", 104.0). The full structure of 5 was confirmed by comparing its spectral data with those reported in the literature ${ }^{31}$.

Luteolin $^{20}$, quercetin 3-O- $\alpha$-L-rhamnopyranoside ${ }^{17,22}$ and quercetin-3-O- $\beta$-D-galactopyranoside ${ }^{22}$ were previously reported from $A$. julibrissin. This is the first reported occurrence of quercetin-3-O- $\beta-D$ glucopyranoside and quercetin-3-O- $(2 "-\mathrm{O}-\beta-\mathrm{D}-$ xylopyranosyl)- $\beta$-D-galactopyranoside in genus albizia.

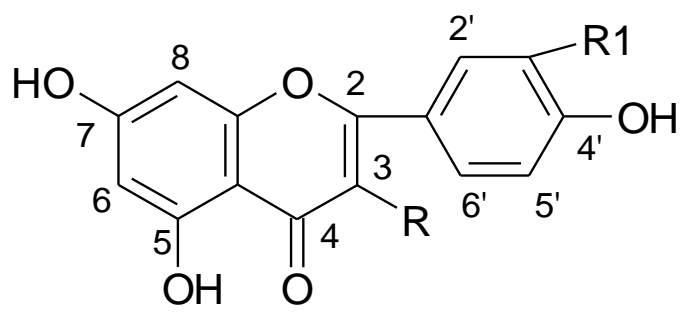

\begin{tabular}{|c|c|c|}
\hline & R & R1 \\
\hline 1 & $\mathrm{H}$ & $\mathrm{OH}$ \\
\hline 2 & O- $\alpha$-L-Rhamnopyranosyl & $\mathrm{OH}$ \\
\hline 3 & O- $\beta$-D-Galactopyranosyl & $\mathrm{OH}$ \\
\hline 4 & O- $\beta$-D-Glucopyranosyl & $\mathrm{OH}$ \\
\hline 5 & O- $\beta$-D-xylopyranosyl-( $\rightarrow 2)-\beta$-D-galactopyranosyl & $\mathrm{OH}$ \\
\hline
\end{tabular}




\section{References}

1) Watt, J.M. Breyer-brandwijk, M.C. (1962). Medicinal and poisonous Plants of South and East Africa. Second ed. Livingstone, Edinburgh, p. 553.

2) Chadha, Y.R. (ed.) (1985). Vol. 1-A, p. 126. CSIR, New Delhi.

3) Pal, B.C., Achari, B., Yoshikawa, K., Arihara, S. (1995) Phytochemistry 38, 1287.

4) Ikeda, T., Fujiwara, S., Kinjo, J., Nohara, T., Ida, Y., Shoji, J., Shingu, T., Isobe, R. and Kajimoto, T. (1995) Bull Chem Soc Jpn 68, 3483.

5) Ma, L., Tu, G., Chen, S., Zhang, R., Lai, L., Xu, X., Tang, Y. (1996) Carbohydrate Research 281, 35.

6) Yoshikawa, K., Satou, Y., Tokunaga, Y., Tanaka, M., Arihara, S., Nigam, S. K. (1998) J. Nat. Prod. 61, 440.

7) Liang, H., Tong, W., Zhao, Y., Cui, J., Tu, G. (2005) Bioorganic \& Medicinal Chemistry Letters 15, 4493.

8) Zheng, L., Zheng, J., Zhao, Y., Wang, B., Wu, L., Liang, H. (2006) Bioorganic \& Medicinal Chemistry Letters 16, 2765.

9) Melek, F.R., Miyase, T., Ghaly, N.S., Nabil, M. (2007) Phytochemistry 68: 1261.

10) Liu, R., Ma, S., Yu, S., Pei, Y., Zhang, S., Chen, X., Zheng, J. (2009a) Journal of Natural products 72: 632.

11) Miyase, T., Melek, F.R., Ghaly, N.S., Warashina, T., El-Kady, M., Nabil, M. (2010) Phytochemistry 71: 1375 .

12) Cheng, Z.Q., Yang D., Liu, Y.Q., Hu, J.M., Jiang, H.Z., Wang, P.C., Li, N., Zhou, J., Zhao, Y.X. (2010) Journal Brazilian Chemical Society 21, 1766.

13) Rukunga, G.M., Waterman, P.G. (1996) Bulletin of the Chemical Society of Ethiopia 10(1), 47.

14) El-Mousallamy, A.M. (1998) Phytochemistry 48, 759.
15) Yadava, R. N., Tripathi, P. (1999) J. Inst. Chem. 71, 202.

16) Yadava, R. N., Tripathi, P. (2000) Res. J. Chem. Environ. 4, 57.

17) Li, Z.P., Gao, S., Hao, C.S., Fan, G.M. (2000) Zhongguo Zhong Yao Za Zhi 25, 103.

18) Rao, Y.K., Reddy, M.V.B., Rao, C.V., Gunasekar, D., Blond, A., Caux, C., Bodo, B. (2002) Chem. Pharm. Bull. 50, 1271.

19) Pandey, M.K., Pandey, R., Singh, V.P., Pandey, V.B., Singh, U.P. (2002) Mycobiology 30, 55.

20) Jung, M.J., Chung, H.Y., Kang, S.S., Choi, J.H., Bae, K.S., Choi, J.S. (2003) Arch. Pharm. Res. 26, 458.

21) Jung, M.J., Kang, S.S., Jung, H.A., Kim, G.J., Choi, J.S. (2004) Arch. Pharm. Res. 27, 593.

22) Lau, C.S., Carrier, D.J., Beitle, R.R., Bransby, D.I., Howard, L.R., Lay, J. J.O., Liyanage, R., Clausen, E.C. (2007). Bioresource Technology 98: 429.

23) Ito, A., Kasai, R., Yamasaki, K., Duc, N.M., Nham, N.T. (1994) Phytochemistry 37, 1455.

24) Ma, Y., Hsiao, S., Chen, H., Hsu, F. (1997) Phytochemistry 46, 1451.

25) Liu, R., Yu, S., Pei, Y. (2009b) Zhongguo Zhong Yao Za Zhi 34(16): 2063.

26) Orsini, F., Pelizzoni, F., Pulici, M., Verotta, L. (1989) Gazz. Chim. Ital 119, 63.

27) Harborne, J.B. (1993) p. 589-618. "The Flavonoids: Advances in Research since 1986". Chapman and Hall, London.

28) Markham, K.R., Ternai, B., Stanley, R., Geiger, H., Mabry, T.J. (1978) Tetrahedron 34: 1389.

29) Asen, A., Horowitz, R.M. (1977) Phytochemistry 16, 147.

30) Yasukawa, K., Takido, M. (1987) Phytochemistry 26, 1224.

31) Larsen, L.M., Nielsen, J.K., Sorensen, H. (1982) Phytochemistry, 21, 1029 